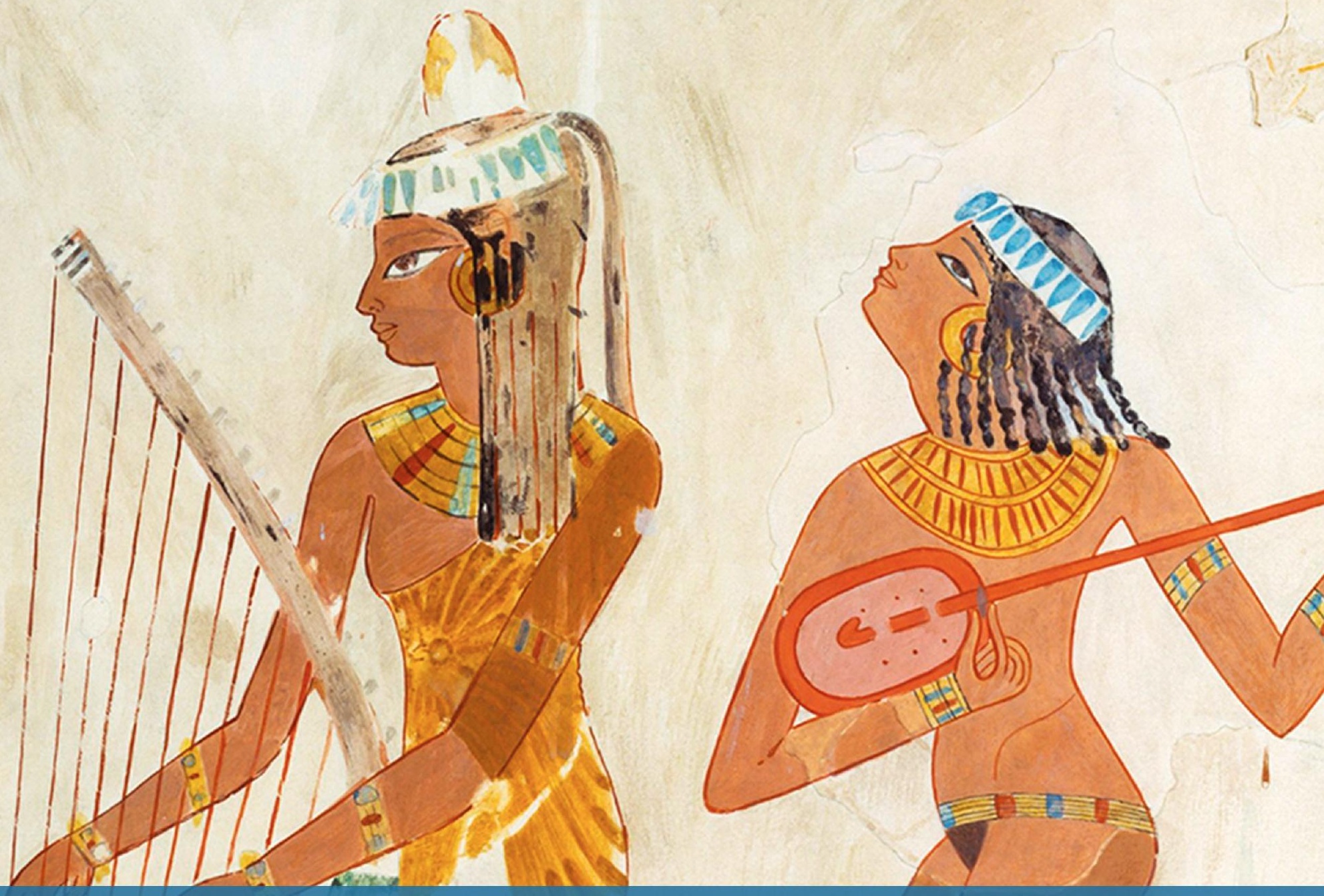

Revista digital de ciencia y Didáctica de la Historia

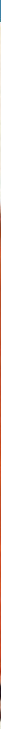




\section{Panta Rei \\ Revista Digital de Ciencia \\ y Didáctica de la Historia}

\section{9}

Revista anual

Fecha de inicio: 1995

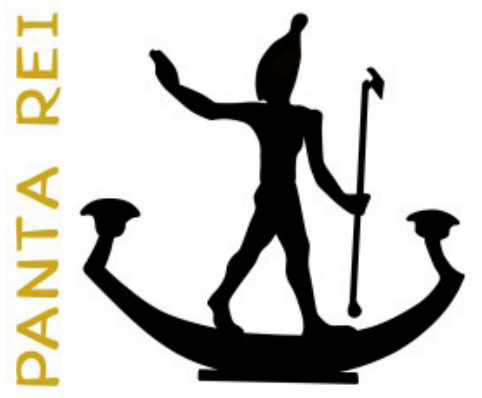

Revista Panta Rei. pantarei@um.es

Edita:

Centro de Estudios del Próximo Oriente y la

Antigüedad Tardía - CEPOAT

Edificio Universitario Saavedra Fajardo.

Universidad de Murcia

C/ Actor Isidoro Máiquez, 9

30007 - MURCIA - ESPAÑA

Teléfono: (+34) 868883890

cepoat@um.es

Web: www.um.es/cepoat/pantarei

Edición 2019

ISSNe: 2386-8864

Responsable de la presente edición: Consejo Editorial Panta Rei.

UNIVERSIDAD DE MURCIA centro de estudios del próximo oriente y la antigüedad tardía

En Portada: Fragmento de pintura de la tumba de Djeserkareseneb (TT38), Tebas. (fotografía del Metropolitan Museum).

Responsables de los textos: Sus autores.

ISSN: 1136-2464

Depósito legal: MU-966-1995 


\section{CONSEJO DE REDACCIÓN}

\section{Coordinador editorial}

Egea Vivancos, Alejandro

[Didáctica de las Ciencias Sociales, UMU]

\section{Editores}

Jiménez Vialás, Helena

[UMU]

López Muñoz, Dámaris

[UJA]

Meseguer Gil, Antonio José

[CEPOAT, UNED]

Sáez Giménez, David Omar

[CEPOAT, UMU]

Sánchez Mondéjar, Celso Miguel

[Patrimonio Inteligente]

\section{Secretaria}

Arias Ferrer, Laura

[Didáctica de las Ciencias Sociales, UMU]

\section{Responsable informático}

Martínez García, José Javier

[CEPOAT, UMU]

\section{Traducción y corrección lingüística}

Martínez Martínez, Cristina

[Sociedad Española de Lenguas Modernas]

Albaladejo Albaladejo, Sara

[ISEN, UMU]

\section{CONSEJO ASESOR}

Adroher Auroux, Andrés María [Arqueología, Universidad de Granada]

Albero Muñoz, M. ${ }^{a}$ del Mar [Historia del Arte, Universidad de Murcia]

Alia Miranda, Francisco [Historia Contemporánea, UCLM]

Arciniega García, Luis [Historia del Arte, Universidad de Valencia]

Barrio Barrio, Juan Antonio [Historia Medieval, Universidad de Alicante]

Castellano i Solé, Núria [Egiptología, Schola Didàctica Activa S.L.]
Chapman, Arthur [History Education, University College of London, Reino Unido]

Cid López, Rosa María [Historia Antigua, Universidad de Oviedo]

Cobacho López, Ángel [Derecho, Universidad de Murcia]

Cuenca López, José María [Didáctica de las Ciencias Sociales, Universidad de Huelva]

Egea Bruno, Pedro M. ${ }^{a}$ [Historia Contemporánea, Universidad de Murcia]

Feijoo Martínez, Santiago [Arqueología, Consorcio Ciudad Monumental de Mérida]

García Atienzar, Gabriel [Prehistoria, Universidad de Alicante]

Ginestí Rosell, Anna [Filología Clásica, Katholische Universität Eichstätt-Ingolstadt]

González Monfort, Neus [Didáctica de las Ciencias Sociales, Universidad Autónoma de Barcelona]

González Soutelo, Silvia [Arqueología, Universidad de Vigo]

Haber Uriarte, María [Prehistoria, Universidad de Murcia]

Hernández de la Fuente, David [Historia Antigua, Universidad Complutense]

Hutson, Scott R. [Anthropology, University of Kentucky, EE UU]

Igual Luis, David [Historia Medieval, UCLM]

Irigoyen López, Antonio [Historia Moderna, Universidad de Murcia]

Jover Maestre, Francisco Javier [Prehistoria, Universidad de Alicante]

Mahony, Simon [Digital Humanities, University College of London, Reino Unido]

Marsilla de Pascual, Francisco Reyes [Técnicas historiográficas, Universidad de Murcia]

Martínez-Burgos García, Palma [Historia del Arte, UCLM]

Mathis, Christian [Didaktik der Geschichte, PH Zürich]

Miralles Maldonado, José Carlos [Filología Clásica, Universidad de Murcia]

Molina Gómez, José Antonio [Historia Antigua, Universidad de Murcia]

Mónica Ghirardi [Historia Moderna, Universidad Nacional de Córdoba, Argentina]

Navarro Espinach, Germán [Historia Medieval, Universidad de Zaragoza]

Noguera Celdrán, José Miguel [Arqueología, Universidad de Murcia]

Ortiz Heras, Manuel [Historia Contemporánea, UCLM]

Panzram, Sabine [Historia Antigua, Universität Hamburg]

Pérez Molina, Miguel Emilio [Filología Clásica, Universidad de Murcia]

Prados Martínez, Fernando [Arqueología, Universidad de Alicante]

Sánchez Ibáñez, Raquel [Didáctica de las Ciencias Sociales, Universidad de Murcia]

Sancho Gómez, Miguel Pablo [Educación, UCAM]

Victoria Moreno, Diego [Historia Contemporánea, UNED]

Vilar García, María José [Historia Contemporánea, Universidad de Murcia]

Vivas Sainz, Inmaculada [Historia del Arte, UNED]

Zamora López, José Ángel [Próximo Oriente Antiguo, CCHS-CSIC] 



\section{Índice}

\section{Artículos}

La imagen de la Prehistoria en el cine y los géneros del cine prehistórico. Un mundo de hombres mono, bikinis y dinosaurios.

Alberto Lombo Montañés.

Trabajo y roles de género durante la Prehistoria. Un estudio sobre su percepción en el alumnado de Historia.

María Pastor Quiles y Daniel Mateo Corredor.

Memoria cultural en el Egipto Faraónico. Algunas reflexiones sobre su origen, función y pervivencia histórica.

Antonio Pérez Largacha.

La representación de la danza dentro de las escenas de banquete de las tumbas tebanas privadas de la XVIII dinastía egipcia.

Miriam Bueno Guardia.

La "Sala del Fresco" de Micenas. Revisión de las interpretaciones del programa iconográfico y nueva lectura en relación a los espacios.

Pelayo Huerta Segovia.

Las advertencias de Quilón y Solón sobre la tiranía de Pisístrato.

Unai Iriarte.

La Virgen de la Leche. Arquetipo de mujer y madre en la pintura del Renacimiento español.

Patricia Castiñeyra Fernández

Innovación didáctica en Historia: un estado de la cuestión en torno a cuatro ejes temáticos.

Diego Luna Delgado.

\section{Reseñas}

Foster, B. R. (2016), The Age of Agade. Inventing empire in ancient Mesopotamia, Londres y Nueva York: Routledge, 438 págs.

Juan Álvarez García.

Alviz Fernández, M. y Hernández de la Fuente, D. (Eds.) (2017). De ópos a limes: el concepto de frontera en el mundo antiguo y su recepción. Madrid: Escolar y Mayo editores. 256 págs.

Ethan Yepes de la Hoz.

Clares Clares, M ${ }^{\mathrm{a}}$ E. (2017). Música y noches de moda. Sociedades, cafés y salones domésticos de Murcia en el siglo XIX. Murcia: Universidad de Murcia, Servicio de Publicaciones. 474 págs.

Elena Micó Terol 195

Goñi Zabalegui, A. (2018). Género y sociedad en el Egipto romano. Una Mirada desde las cartas de mujeres. Oviedo: Ediciones de la Universidad de Oviedo. 360 págs.

Alejandra Izquierdo Perales. 199

Normas de publicación/Publishing rules 



\title{
Trabajo y roles de género durante la Prehistoria. Un estudio sobre su percepción en el alumnado de Historia $^{1}$
}

\author{
Work and Gender Roles During Prehistory. A Study about Their Perception in \\ History Students
}

\author{
Pastor Quiles, María \\ Universidad de Alicante \\ Mateo Corredor, Daniel ${ }^{3}$ \\ Universidad de Alicante
}

Recibido: 10/07/2018

Aceptado: 01/03/2019

Para citar este artículo: Pastor Quiles, M. y Mateo Corredor, D. (2019). Trabajo y roles de género durante la Prehistoria. Un estudio sobre su percepción en el alumnado de Historia. Panta Rei. Revista Digital de Ciencia y Didáctica de la Historia, 37-53.

ISSNe: 2386-8864

DOI: $10.6018 /$ pantarei/2019/02

\begin{abstract}
Resumen
Desde la arqueología tradicional se ha generado una imagen de la Prehistoria en la que se atribuyen de forma marcada a mujeres u hombres trabajos y roles, frecuentemente influenciada por concepciones contemporáneas. Con este artículo analizamos la percepción del alumnado del Grado en Historia sobre una serie de afirmaciones, presentadas en un cuestionario con una escala tipo Likert, que relacionan actividades con un sexo u otro en contextos prehistóricos. Esta investigación ha permitido conocer la presencia entre el alumnado de algunas de estas visiones estereotipadas. Se evidencia la necesidad de incorporar la perspectiva feminista a los estudios históricos para tratar de ser conscientes en mayor medida de estos estereotipos que condicionan la imagen que tenemos de la Prehistoria.
\end{abstract}

\section{Palabras clave}

Arqueología, educación, cuestiones de género, feminismo, estereotipos sexuales.

\footnotetext{
Abstract

From traditional archaeology an image of Prehistory has been transmitted where activities and roles are attributed to women or men, frequently influenced by contemporary conceptions. In this paper we analyse the perceptions of History students about a series of statements, presented in a

1 El presente trabajo se ha realizado dentro de los proyectos HAR2015-64601-C3-2-R, HAR2015-68554-P, HAR2016-76586-P, financiados por el Ministerio de Economía y Competitividad y el proyecto GRE-16-06, financiado por la Universidad de Alicante.

2 Para contactar con esta autora: María Pastor Quiles. Universidad de Alicante. m.pastor@ua.es.

3 Para contactar con este autor: Daniel Mateo Corredor. Universidad de Alicante. daniel.mateo@ua.es.
}

Panta Rei (2019), 37 - 53 
questionnaire based on a Likert rating scale. These statements associate activities with one sex or the other in prehistoric contexts. This research has allowed us to acknowledge the presence of some of these stereotyped visions among the students. The need of incorporating the feminist perspective into historical studies is highlighted, in order to be able to identify these stereotypes that constrain the image we have of prehistoric times.

\section{Keywords}

Archaeology, Education, Gender Issues, feminism, Sex Stereotypes.

\section{Introducción}

Al contrario de lo que ocurre con otras épocas del pasado, el conocimiento acerca de la Historia humana previa al uso de la escritura no se obtiene a partir de una variedad de fuentes, sino que depende del estudio de los restos arqueológicos. La arqueología permite conocer el uso y el desarrollo de tecnologías y procesos productivos durante la Prehistoria, que conllevaron actividades o trabajos. En este campo, puede considerarse que, por parte de la arqueología tradicional, se han establecido jerarquías entre las diferentes actividades, siendo unas altamente valoradas, mientras que a otras se les ha atribuido una importancia muy escasa o apenas han sido objeto de atención. De este modo, puede observarse una correlación entre las actividades consideradas de gran relevancia, incluso cruciales para la propia evolución de la Humanidad, y su desempeño por parte de los hombres, mientras que a las mujeres de la Prehistoria se les ha atribuido un papel muy secundario en sus grupos desde los orígenes de la disciplina, como lleva siendo resaltado desde hace décadas (Conkey y Spector, 1984).

En el campo de las relaciones humanas en contextos prehistóricos, son muchas las cuestiones que se desconocen o cuyo conocimiento es muy limitado. Entre ellas está la existencia de relaciones desiguales de poder entre mujeres y hombres y su grado de instauración social en función de cada contexto, o de una distribución de trabajos en función del sexo y de un establecimiento de roles diferenciados -de género- en el seno de cada sociedad. No obstante, a pesar de que en la mayoría de los casos la arqueología prehistórica no posea evidencias, por ejemplo, de si un determinado trabajo fue realizado especialmente por un sexo u otro, la atribución de actividades productivas a mujeres y hombres tiene una larga tradición. En este sentido, han sido diversos los trabajos que han llamado la atención acerca de que la marcada diferenciación de roles y actividades que se han dado por supuestos y se han establecido para la Prehistoria, provienen en gran medida de la interiorización de la desigualdad entre sexos en el presente (Montón, 2000; Moser, 1993; Owen, 2005; Zihlman, 1981). En la actualidad, la conceptualización de los estereotipos de género permite que seamos conscientes de la asociación tradicional, en el seno de las sociedades patriarcales, de los hombres con características como actividad, fuerza, agresividad o inteligencia, mientras que las mujeres han sido asociadas con pasividad, debilidad, vulnerabilidad o emocionalidad. De este modo, se justifican unos roles diferenciados en lo social y, así, el dominio y liderazgo masculino y la relación entre las mujeres y lo "doméstico" (ver, por ejemplo, Bosch y Ferrer, 2003).

La investigación que aquí presentamos se ha desarrollado en el contexto de un proyecto destinado a conocer y analizar los conocimientos y la percepción que tiene el alumnado del Grado en Historia de la Universidad de Alicante acerca de la desigualdad entre mujeres y hombres, tanto en el presente, como en el pasado (Pastor y Mateo, 2018), particularmente, en la Prehistoria y la Antigüedad, abordando en este espacio los resultados obtenidos referentes a cronologías prehistóricas. Así, el principal objetivo de este trabajo es conocer la percepción del alumnado del Grado en Historia acerca de una serie de cuestiones que atribuyen determinados trabajos, manifestaciones o actitudes a mujeres u hombres en contextos prehistóricos. Además, se evalúa si se producen diferencias en las respuestas en función del sexo y de la edad de los alumnos y alumnas, así como entre quienes están finalizando sus estudios y quienes acaban de comenzarlos. Consideramos especialmente importante plantear al alumnado de Historia cuestiones como las 
que más adelante se muestran y conocer sus reacciones y valoraciones, dada su amplia presencia en relación con la Prehistoria, su relevancia y sus implicaciones, de cara al conocimiento de las sociedades prehistóricas, pero también más allá de él.

En las respuestas del alumnado pueden influir múltiples factores. Por un lado, posiblemente los tiempos prehistóricos son la etapa de la Historia de la Humanidad en cuya percepción social más ha influido la ficción creada en torno a ellos. Así, el interés mostrado por el público acerca de la Prehistoria se produce de la mano, en muchas ocasiones, de concepciones no reales acerca de esta etapa histórica -como la relación entre seres humanos prehistóricos y dinosaurios (Wood, 1996; Venegas, 2017)-, reforzadas por medios y recursos culturales y de ocio con tanta influencia como el cine (Jardón, Pérez y Soler, 2012; Lombo, Catalán, Palacios y Parrilla, 2014). Estas imágenes también incluyen marcados estereotipos de género. En este sentido, desde la infancia se configura un "imaginario prehistórico" generado al contacto con los recursos comentados, que es necesario conocer y tener en cuenta a la hora de plantear la enseñanza de la Prehistoria (Ruiz, 2010) y que, en el caso de las consideraciones sobre hombres y mujeres en ese periodo histórico, es especialmente importante.

No obstante, los tiempos prehistóricos suscitan al mismo tiempo otro tipo de interés por parte del público, al ser la Prehistoria donde se ubican los orígenes de los seres humanos y donde pueden llegar a encontrarse claves que contribuyan a explicar "lo que somos". En los museos arqueológicos, la Prehistoria inicia los recorridos por las diferentes salas, marcando lo que son considerados como los primeros pasos del camino de la Humanidad hasta nuestros días, un inicio que, además, tiene por lo general un importante carácter androcéntrico. El hecho de que la Prehistoria se conciba como la etapa histórica en la que se genera lo que somos hoy tiene una enorme importancia y puede actuar como forma de justificar y legitimar comportamientos (Conkey y Spector, 1984; GiffordGonzalez, 1993; González, 2009; entre otros), también en lo que se refiere a la desigualdad entre hombres y mujeres.

Por otro lado, la atribución de estereotipos de género en la Prehistoria no se da exclusivamente fuera del ámbito académico. El propio androcentrismo de los estudios históricos ha generado una imagen sesgada del pasado y los tiempos prehistóricos no son una excepción. Así, por ejemplo, en lo referente a los grupos humanos del Paleolítico, desde la academia se ha reproducido tradicionalmente el modelo del hombre/macho protector y cazador, que provee el alimento a mujeres/ hembras pasivas y sumisas (Conkey, 1991; Dahlberg, 1981; Leibowitz, 1975; Owen, 2005), lo que ha quedado plasmado en las representaciones visuales de esos grupos en los diversos recursos utilizados para la transmisión del conocimiento arqueológico y especialmente en los museos (CintasPeña, García Sanjuán y Morell, 2018; Moser, 1993; Querol y Hornos, 2015; Soler, 2009).

Además, como ha sido resaltado en distintos trabajos, la impartición de contenidos acerca de la Prehistoria en los niveles educativos preuniversitarios, en la enseñanza primaria y secundaria, ha sido, por lo general, considerablemente escasa en el ámbito español (Ruiz y Álvarez, 1997; Ruiz, 2010), como también ha ocurrido fuera de él (Wood, 1996). Asimismo, los materiales didácticos sobre la Prehistoria tienen, en su mayoría, un marcado carácter tradicional y fuertemente androcéntrico.

Por todo ello, consideramos de vital importancia acercarnos a la percepción, visiones y opiniones que sobre este tema poseen los futuros historiadores e historiadoras, considerando sobre todo la importante posición que podrán ocupar en la transmisión y divulgación del conocimiento histórico a la sociedad. De este modo, es clave la formación que este alumnado reciba, pues sus conocimientos y actitudes sobre la desigualdad entre hombres y mujeres a lo largo de la Historia tendrán su reflejo en su posterior desempeño profesional. 


\section{Metodología}

La población del estudio está formada por el alumnado del Grado en Historia de la Universidad de Alicante. La muestra, seleccionada de manera no aleatoria o estratificada, está formada por 108 alumnas y alumnos que formaban parte de los grupos de mañana y tarde de primer y cuarto curso durante el año académico 2016-2017 (Figura 1). El objetivo era poder comparar entre el alumnado que estaba a punto de terminar el Grado en Historia respecto a aquél recién incorporado a la carrera, con el fin de observar la posible existencia de diferencias.
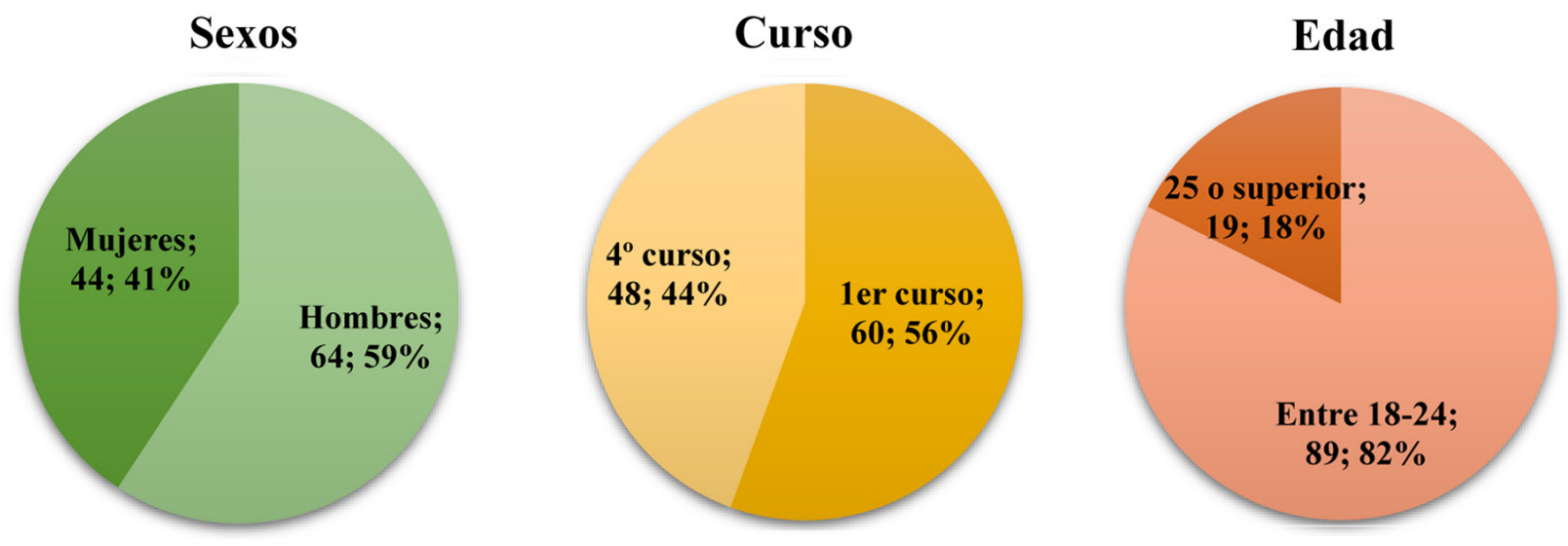

Figura 1: Análisis por categorías de la muestra $(n=108)$. Fuente: elaboración propia.

Hemos utilizado un cuestionario cerrado con una escala de valoración tipo Likert. Es una escala de nivel ordinal y aditiva que se basa en la reacción ante una serie de proposiciones, sobre las que permite medir actitudes, así como el nivel de conformidad (Namakforoosh, 2000). Se trata de un instrumento utilizado con frecuencia en las ciencias sociales y humanísticas, de elaboración sencilla y que tiende a alcanzar una alta fiabilidad (Farrell, Rabinowitz, Wallander y Curran, 1985).

El cuestionario nos ha permitido valorar la percepción y las reacciones del alumnado ante cada una de las afirmaciones propuestas y medir la mayor o menor presencia de estereotipos sexistas. Para cada ítem escogimos una escala de estimación de cinco niveles de acuerdo a las siguientes alternativas mostradas de manera horizontal: 1 (totalmente en desacuerdo); 2 (en desacuerdo); 3 (ni de acuerdo ni en desacuerdo); 4 (de acuerdo); 5 (totalmente de acuerdo). Con el fin de limitar la tendencia a contestar afirmativamente, uno de los sesgos de la escala Likert, incluimos afirmaciones con direcciones en sentido positivo y negativo. Además, las proposiciones de cada tema abordado se presentaron de manera no agrupada, exceptuando las relativas a la valoración de la representación de las mujeres en los contenidos del Grado en Historia, reservados sólo al alumnado de cuarto curso y que ya han sido analizados en otro lugar (Pastor y Mateo, 2018).

Una vez diseñado, el cuestionario se mostró a diversos especialistas y fue realizado a un grupo piloto, lo que permitió eliminar ítems y ajustar los seleccionados, mejorando la validez del instrumento ${ }^{4}$. El cuestionario definitivo está compuesto por 32 proposiciones comunes a ambos grupos y 4 exclusivas del grupo de cuarto curso, con un tiempo de aplicación de en torno a 10/15 minutos. El alfa de Cronbach fue calculado para el conjunto de las proposiciones obteniendo $\alpha=$ 0,793, lo que indica una consistencia interna aceptable (George y Mallery, 2003).

4 Damos las gracias a las personas que participaron en el cuestionario piloto, así como al personal investigador que nos asesoró en la elaboración de su versión final. 
Los cuestionarios fueron presentados al alumnado de ambos cursos al final del segundo semestre del curso 2016-20175. Fueron rellenados de manera anónima, solicitando que nos proporcionaran únicamente sus datos de sexo y edad, que junto al curso constituyen las variables independientes. Tras la aplicación del instrumento se procedió al proceso de codificación y tratamiento cuantitativo de los datos, sometidos a un análisis estadístico que incluía el uso de medidas de tendencia central, dispersión, frecuencias y porcentajes. En el presente trabajo analizaremos los 12 ítems relacionados con la Prehistoria.

Las cuestiones planteadas al alumnado que se abordan en este texto están basadas en consideraciones que frecuentemente recorren las interpretaciones y representaciones de los grupos humanos prehistóricos. Así, somos conscientes de que presentan un carácter globalizador u homogeneizador, ya que lo hacen de acuerdo con la naturaleza de estas consideraciones, que suelen generar y transmitir una idea de la Prehistoria que no refleja el enorme abanico temporal que abarca y la diversidad de grupos humanos y formas de organización social que la integrarían.

\section{Roles de género y atribución de actividades. La percepción del alumnado de Historia}

\subsection{Cuestiones previas: sobre el matriarcado, la dominación masculina y los roles de género en la Prehistoria}

Como marco introductorio para las cuestiones específicas acerca de la atribución de actividades a mujeres y hombres que se recogerán en los siguientes apartados, queremos referirnos a dos afirmaciones referidas a la Prehistoria que ya han sido presentadas (Pastor y Mateo, 2018) y sobre las que deseamos profundizar. Ambos ítems y sus respuestas pueden ponerse en relación, de una forma o de otra, con diferentes visiones existentes acerca de la Prehistoria, que han ido generándose y estableciéndose en la cultura popular, en el ámbito no académico. Estas narrativas e imágenes generan un marco con el que puede relacionarse la atribución de trabajos a hombres o a mujeres en cronologías prehistóricas. La razón para ello es que se encuentran impregnadas por fuertes estereotipos de género, que atribuyen cualidades y actitudes muy distintas a hombres y a mujeres y que no son tan diferentes a los roles de género que se transmiten desde la arqueología prehistórica tradicional (Tabla 1 y Figura 2).

Tabla 1

Ítems con porcentajes de respuesta y promedio por categorías

\begin{tabular}{llcccc}
\hline $\begin{array}{l}\text { Matriarcado, dominación } \\
\text { masculina y roles de } \\
\text { género }\end{array}$ & 1-TED & 2-ED & 3-Ni DA ni ED & 4-DA & 5-TDA \\
\hline $\begin{array}{l}\text { 1. En las primeras } \\
\text { sociedades humanas, el } \\
\text { matriarcado era el sistema } \\
\text { de relación entre sexos } \\
\text { imperante. }\end{array}$ & $7,4 \%$ & $16,7 \%$ & $48,1 \%$ & $25,0 \%$ & $2,8 \%$ \\
$\begin{array}{l}\text { 2. El gradodesometimiento } \\
\text { o subordinación de las } \\
\text { mujeres a los hombres } \\
\text { habría sido mayor en } \\
\text { la Prehistoria que en la } \\
\text { Antigüedad. }\end{array}$ & & & & \\
\hline
\end{tabular}

Fuente: elaboración propia.

5 Agradecemos al profesorado y especialmente a las alumnas y alumnos de estos grupos su generosa disposición y participación, sin las que este proyecto no hubiese sido posible. 

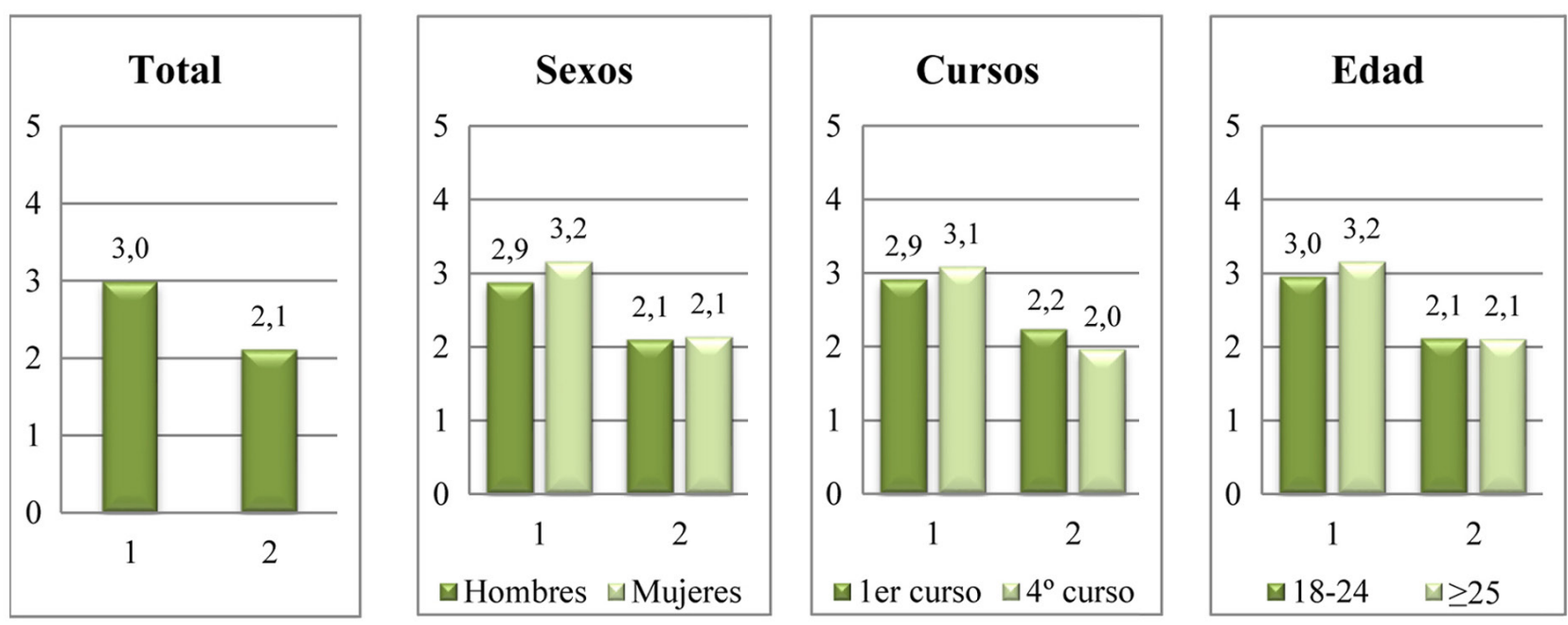

Figura 2: ítems con porcentajes de respuesta y promedio por categorías. Fuente: elaboración propia.

El primero de los ítems que queremos resaltar es el que afirmaba que "en las primeras sociedades humanas, el matriarcado era el sistema de relación entre sexos imperante". Prácticamente la mitad del alumnado encuestado se mostró "ni de acuerdo ni en desacuerdo" y casi el 30\% afirmó estar de acuerdo o muy de acuerdo. Además, las alumnas se mostraron algo más cerca de suscribirlo que los alumnos varones y la idea de que las primeras sociedades prehistóricas fueran matriarcales fue ligeramente más aceptada al final del Grado que entre el alumnado de primer curso.

La existencia en la Prehistoria de un matriarcado -un gobierno de las mujeres o ginecocraciafue una teoría desarrollada por Johann Jakob Bachofen (1861), concebida como una etapa en la evolución de las sociedades que desembocaría, tras su derrota y castigo, en el establecimiento del orden social patriarcal (Rodríguez y Serrano, 2005). La idea de una fase matriarcal en el desarrollo de los grupos humanos fue incorporada en el siglo XIX por otros trabajos de gran repercusión ${ }^{6}$. A pesar de que la existencia de sociedades matriarcales, entendidas en el sentido descrito por Bachofen, no es mayoritariamente considerada por la investigación actual (Lerner, 1990; Rodríguez y Serrano, 2005; entre otros), la idea parece estar presente en el imaginario colectivo, reflejándose con cierta fuerza en el alumnado del Grado de Historia e incluso con mayor intensidad en el de cuarto curso.

La idea de un gobierno de las mujeres ya fue planteada en la Antigüedad clásica con el mito de las amazonas, que no estaban sometidas a la autoridad masculina, desempeñaban actividades y trabajos que se consideraban propios de los hombres y que acababan siendo vencidas (Roque, 2017). Existen también otros mitos y relatos en otros contextos temporales y geográficos que narran el origen del dominio de los hombres sobre las mujeres, actuando para legitimarlo y reproducirlo (Rodríguez y Serrano, 2005). Narran un gobierno inicial de la sociedad por parte de las mujeres, que supone un peligro y es sustituido por el gobierno de los hombres, que someten a las mujeres y traen el "orden" patriarcal, siendo castigados los intentos de rebelión.

Un elemento que relatos como el de las amazonas resaltan es la definición de una clara dualidad entre lo masculino y lo femenino (Roque, 2017), rígidamente establecida, como identidades a las que se atribuyen características muy distintas, incluso opuestas, mediante lo que hoy llamamos estereotipos de género, que alimentan los distintos roles atribuidos a mujeres y

6 Como La sociedad antigua de Lewis Henry Morgan (1877) o El origen de la familia, la propiedad privada y el estado de Friedrich Engels (1884). 
hombres. La atribución de características y roles sociales diferenciados se plasma en la distribución de actividades en función del sexo, asociando a hombres y a mujeres aquellos trabajos que, de acuerdo con las características que se han establecido como relativas a cada sexo, se considera que es apropiado que desempeñen y/o que son capaces de desempeñar.

La Prehistoria, como contexto lejano e incluso remoto en el tiempo, se presenta en distintas manifestaciones como un marco propicio en el que plantear escenarios muy distintos a los contemporáneos en cuanto a las relaciones entre los sexos y las atribuciones de género, algo simbolizado en la idea del matriarcado. En el cine ambientado en la Prehistoria se trata el matriarcado, por ejemplo, en la película Prehistoric women (1950), que muestra a un grupo formado sólo por mujeres que realiza con éxito todas las actividades para su supervivencia hasta que entran en contacto con hombres, aunque aquéllas, de forma voluntaria, deciden abandonar su forma de vida previa y someterse a ellos (Soler, 2012). La lejanía como característica del escenario propicio para plantear una inversión de los roles de género también puede ser geográfica, como en la novela utópica Herland de Charlotte Perkins Gilman (1915) que confronta una sociedad próspera y moderna, creada y compuesta sólo por mujeres, con los planteamientos de género europeos de inicios del siglo XX. Es relevante destacar cómo en estas producciones lo extraño y revolucionario es el hecho en sí de que las mujeres sean capaces de producir y de sacar adelante una sociedad por sí mismas.

Por otro lado, entre las cuestiones a valorar en nuestro estudio se encontraba un ítem que afirmaba que la dominación de las mujeres por parte de los hombres habría sido mayor en la Prehistoria que en la Antigüedad, sobre lo que el $75 \%$ del alumnado se mostró en desacuerdo o muy en desacuerdo, coincidiendo con lo generalmente considerado por la investigación (Lerner, 1990; Hernando, 2005; entre otros). En efecto, la sociedad romana, por ejemplo, se caracterizó por una gran desigualdad entre hombres y mujeres, institucionalizada y visible en ámbitos como el político o el jurídico, ampliamente constatada en las fuentes históricas. No obstante, mediante el proyecto de investigación en el que se enmarca este artículo, hemos podido observar que el conocimiento que se posee en la actualidad acerca de muchas de las cuestiones que caracterizan dicha desigualdad entre sexos en la antigua Roma no necesariamente se refleja en los conocimientos manifestados por el alumnado (Mateo y Pastor, 2019).

No obstante, ante dicho ítem un $17,6 \%$ de las alumnas y alumnos se mostraban "ni de acuerdo ni en desacuerdo" y un 7,4\% daban por válido este enunciado. Consideramos que estas respuestas, aunque no fueran las mayoritarias, también merecen ser objeto de atención, entendiendo que pueden estar relacionadas, entre otras cuestiones, con imágenes estereotipadas que se transmiten acerca de la Prehistoria, desde hace décadas, en producciones culturales de distinto tipo. Generalmente, estas producciones coinciden en presentar la Prehistoria -centrándose en la Prehistoria más antigua- como un entorno adverso para los humanos, lleno de peligros, donde los hombres, generalmente asociados a características como la fuerza y la brutalidad-cualidades del "cavernícola"-, son los que luchan por la supervivencia del grupo. La violencia masculina es un elemento omnipresente en estas representaciones, que se han transmitido a través del cine (Jardón y Pérez, 2012; Lombo et al., 2014), del cómic (Ruiz, 1997), o de los videojuegos (Venegas, 2017) de temática prehistórica.

Esta violencia de los hombres también se asume en relación con las mujeres. Así, se han generado y reproducido escenas como la que muestra a hombres cargando contra su voluntad a mujeres o arrastrándolas del pelo. Estas imágenes son mostradas como "representativas" de la Prehistoria, cuando aparecen con frecuencia en viñetas, en la portada de películas clásicas que tratan la Prehistoria como The Three Ages (1936) o cuando son la manera de conseguir puntuación en videojuegos ambientados en tiempos prehistóricos como BC. Bill (1984) (Venegas, 2017). Esta imagen de superioridad y fuerza masculina, frente a inferioridad y vulnerabilidad femenina en las representaciones no académicas de la Prehistoria queda fomentada, además, por la presencia de otros modelos frecuentes, como el que representa al hombre como protagonista y héroe salvador del personaje secundario, una mujer bella e indefensa, que ha sido capturada (Jardón et 
al., 2012, Venegas, 2017). Esta narrativa se encuentra en otras recreaciones de mundos perdidos de inspiración prehistórica, como la del famoso King Kong. Además, las mujeres prehistóricas aparecen desempeñando roles de género tradicionales y de sumisión a los varones en muchas producciones audiovisuales de ambientación prehistórica, incluyendo series de dibujos animados como The Flintstones (Los Picapiedra) o Il était une fois... l'Homme (Érase una vez... el Hombre), que empezaron sus emisiones en 1960 y 1978 respectivamente.

\subsection{Trabajo y roles de género: Prehistoria antigua}

En este apartado presentamos los ítems valorados por el alumnado que se relacionan principalmente, aunque no de forma exclusiva, con el Paleolítico o Prehistoria antigua (Tabla 2 y Figura 3).

Tabla 2

Ítems con porcentajes de respuesta y promedio por categorías

\begin{tabular}{lccccc}
\hline \multicolumn{1}{c}{ Prehistoria antigua } & 1-TED & 2-ED & $\begin{array}{c}\text { 3-Ni DA ni } \\
\text { ED }\end{array}$ & 4-DA & 5-TDA \\
\hline $\begin{array}{l}\text { 3. La recolección durante el } \\
\text { Paleolítico habría sido un trabajo }\end{array}$ & & & & & \\
hecho por mujeres, mientras que & $3,7 \%$ & $23,1 \%$ & $15,7 \%$ & $38,9 \%$ & $18,5 \%$ \\
la caza sería llevada a cabo por \\
hombres.
\end{tabular}

En el cuestionario incluimos la afirmación "la recolección durante el Paleolítico habría sido un trabajo hecho por mujeres, mientras que la caza sería llevada a cabo por hombres". Esta frase, formulada de manera categórica, ha sido rechazada por aproximadamente el $27 \%$ del alumnado, mostrándose un $16 \%$ "ni de acuerdo ni en desacuerdo". Casi un $60 \%$ de las y los estudiantes encuestados se han mostrado de acuerdo o totalmente de acuerdo con ella. Las alumnas tienden a aceptarla algo más que los alumnos varones, con una pequeña diferencia de dos décimas, la misma cifra con la que los alumnos más jóvenes tienden a darla por válida en mayor medida que el grupo con edades a partir de los 25 años. En una comparación entre los grupos de primero y de cuarto, existe una diferencia más significativa, de seis décimas, situándose más cerca de aceptar esta concepción estereotipada el alumnado que inicia sus estudios en Historia, sin que, en todo caso, haya ningún grupo que se manifieste en contra de forma mayoritaria. 

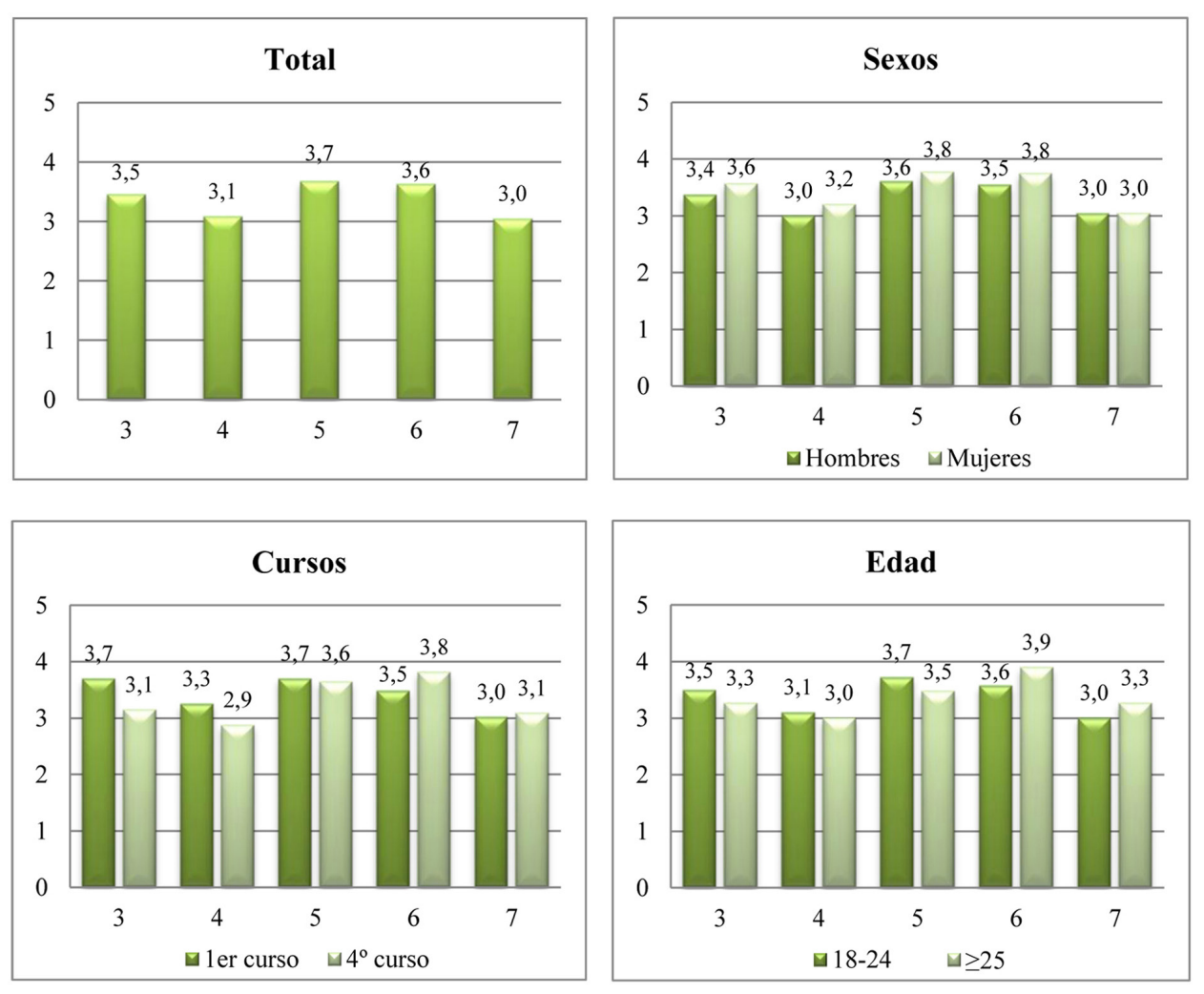

Figura 3: ítems con porcentajes de respuesta y promedio por categorías. Fuente: elaboración propia.

El binomio hombres cazadores versus mujeres recolectoras, es posiblemente el exponente más claro de la división sexual del trabajo en función del sexo que se ha establecido tradicionalmente para la Prehistoria antigua y que hoy en día se encuentra mayoritariamente vigente. Esta asumida distribución de las actividades económicas consideradas principales en los primeros grupos humanos, entre los hombres cazadores y las mujeres recolectoras -y cuidadoras de la descendencia-, se produciría a partir de finales de la década de los 60 (Estioko-Griffin y Griffin, 1981). Con anterioridad, se encontraba asentado el modelo del "hombre cazador", nacido de la teoría evolucionista moderna, pero no se consideraba el papel de la recolección, ni tampoco el trabajo de las mujeres como recolectoras (Bolger, 2006), como parte del modelo que más tarde se asentaría. Además, la caza, concebida como una actividad desarrollada por hombres, se presentaba como un detonante fundamental del desarrollo de aptitudes que permitirían el desarrollo del ser humano, incluida la inteligencia (Slocum, 1975; Bolger, 2006; Kästner, 2009). Desde hace décadas, diferentes trabajos han cuestionado el modelo rígido basado en una marcada división por sexos, resaltando la necesidad de considerar una mayor variedad, flexibilidad y complejidad en las estrategias de subsistencia (Dahlberg, 1981; Spector, 1999; Owen, 2005; entre otros). A pesar de ello, el modelo de hombres cazadores y mujeres recolectoras permanece vigente en los discursos e imágenes de la Prehistoria, siendo excepcional la representación de mujeres cazadoras, e igual o más excepcional la de hombres recolectores, y esta vigencia se ha manifestado en las respuestas ofrecidas por el alumnado.

Por otra parte, también forma parte del cuestionario la siguiente frase: "Durante la Prehistoria, las mujeres se habrían dedicado mayoritariamente al cuidado de su descendencia y, por lo tanto, la mayor parte de las actividades productivas habrían sido realizadas por los hombres". Este ítem recoge una idea reflejada en gran parte de los discursos y representaciones acerca de la vida en la Prehistoria en las que las mujeres quedan asociadas, en la gran mayoría de los casos, a algunas "tareas" realizadas en el ámbito del "hogar", considerándose limitadas por su actividad reproductiva 
(Moser, 1993; Owen, 2005), de las que bien se puede concluir que el "verdadero" trabajo sería un campo eminentemente masculino. Los resultados indican un curioso empate, con un $42,6 \%$ del alumnado que se sitúa de acuerdo o muy de acuerdo, y una cifra igual que dice estar en desacuerdo o muy en desacuerdo. Como en el caso anterior, existe una pequeña diferencia de dos décimas, con la que las alumnas muestran una mayor aceptación que los alumnos, siendo mayor la diferencia entre cursos, donde se observa una mayor tendencia a validar esta visión tradicional por parte del alumnado de primero, con un 3,3 de promedio, frente al 2,9 de los de cuarto.

De igual modo, el trabajo de la talla lítica en la Prehistoria es sistemáticamente representado como un trabajo masculino, sin considerarse que no sólo los hombres en la Prehistoria habrían necesitado herramientas de piedra y habrían sido capaces de fabricarlas (Gero, 1991; Sassaman, 1998). Cuando planteamos al estudiantado si tanto mujeres como hombres fabricarían herramientas de piedra tallada durante el Paleolítico, casi el $67 \%$ mostraron su conformidad con el enunciado, mientras que un $19,4 \%$ se mostraron en desacuerdo. Esta es la cuestión, entre todas las que tratamos en este artículo, en la que se han obtenido cifras más altas de conformidad a nivel global, lo que indica un alto grado de aceptación del alumnado, más allá de la tendencia a contestar de manera afirmativa en este tipo de test. En una comparación entre alumnos y alumnas, éstas se mostraron algo más de acuerdo con que ambos sexos habrían desarrollado la talla lítica de herramientas en los grupos paleolíticos, mientras que apenas se registraron diferencias entre cursos.

Por su parte, ante la frase "durante la Prehistoria, las niñas trabajarían", el $64 \%$ del alumnado ha mostrado su aceptación, con un $13 \%$ que la rechaza y un notable $23 \%$ que se manifiesta "ni de acuerdo ni en desacuerdo". Las alumnas se muestran más de acuerdo que los varones, con una diferencia de tres décimas -un total de 3,8 puntos-. Una cifra similar arroja la comparación por cursos, mostrándose el alumnado de cuarto más de acuerdo que el de primero en aceptar el trabajo infantil femenino, con 3,8 puntos y tres décimas más de diferencia. También son tres décimas las que muestran la diferencia entre la mayor conformidad del pequeño grupo que posee 25 o más años respecto a la mostrada por el alumnado por debajo de esa edad.

Los desarrollos considerados clave durante la evolución humana y el Paleolítico, desde las características físicas distintivas de los seres humanos hasta el pensamiento simbólico, han sido interpretados y representados gráficamente en términos masculinos, excluyendo a las mujeres de ellos. En este marco, se encuentran también las manifestaciones artísticas (Conkey, 1997; Adovasio, Soffer y Page, 2007; Kästner, 2009). En museos o publicaciones es casi imposible encontrar la imagen de una mujer realizando una pintura rupestre prehistórica, salvo excepciones como la reciente representación realizada por Arturo Asensio para la exposición Arte sin Artistas. Una mirada al Paleolítico, en el Museo Arqueológico Regional de Madrid. En este sentido, quisimos conocer las reacciones del alumnado ante la afirmación: "Las pinturas de la cueva de Altamira probablemente fueron pintadas por mujeres". Esta frase generó un 11,2\% de negación, un 15,8\% de aceptación y un $73 \%$ de respuestas "ni de acuerdo ni en desacuerdo", siendo el ítem que ha generado un mayor número de respuestas intermedias. No se aprecian apenas diferencias entre las categorías analizadas, salvo en el alumnado de mayor edad, que alcanza un promedio de 3,3, tres décimas superior al grupo menor de 25 años.

\subsection{Trabajo y roles de género: Prehistoria reciente}

A continuación, exponemos los resultados de las afirmaciones mayoritariamente relativas a la Prehistoria reciente (Tabla 3 y Figura 4). 
Tabla 3

Ítems con porcentajes de respuesta y promedio por categorías

\begin{tabular}{|c|c|c|c|c|c|}
\hline Prehistoria reciente & 1-TED & 2-ED & $\begin{array}{c}\text { 3-Ni DA ni } \\
\text { ED }\end{array}$ & 4-DA & 5-TDA \\
\hline $\begin{array}{l}\text { 8. Los inicios de la agricultura } \\
\text { habrían podido ser desarrollados } \\
\text { por mujeres, ya que durante } \\
\text { el Paleolítico eran las que } \\
\text { mayoritariamente recolectaban y } \\
\text { se les podría presuponer un mayor } \\
\text { conocimiento sobre las plantas. }\end{array}$ & $0,9 \%$ & $11,1 \%$ & $24,1 \%$ & $55,6 \%$ & $8,3 \%$ \\
\hline $\begin{array}{l}\text { 9. En las sociedades } \\
\text { prehistóricas, los hombres } \\
\text { también desempeñarían un } \\
\text { papel importante en el cuidado y } \\
\text { aprendizaje de su descendencia. }\end{array}$ & $3,7 \%$ & $12,0 \%$ & $21,3 \%$ & $48,1 \%$ & $14,8 \%$ \\
\hline $\begin{array}{l}\text { 10. La mayor parte de la cerámica } \\
\text { prehistórica sería fabricada por } \\
\text { mujeres. }\end{array}$ & $2,8 \%$ & $24,1 \%$ & $44,4 \%$ & $26,9 \%$ & $1,9 \%$ \\
\hline $\begin{array}{l}\text { 11. La producción del metal en la } \\
\text { Prehistoria habría sido realizada } \\
\text { mayoritariamente por hombres. }\end{array}$ & $1,9 \%$ & $13,0 \%$ & $25,9 \%$ & $50,0 \%$ & $9,3 \%$ \\
\hline $\begin{array}{l}\text { 12. En las sociedades } \\
\text { prehistóricas, serían los hombres } \\
\text { los constructores de las viviendas. }\end{array}$ & $4,6 \%$ & $30,6 \%$ & $26,9 \%$ & $29,6 \%$ & $8,3 \%$ \\
\hline
\end{tabular}
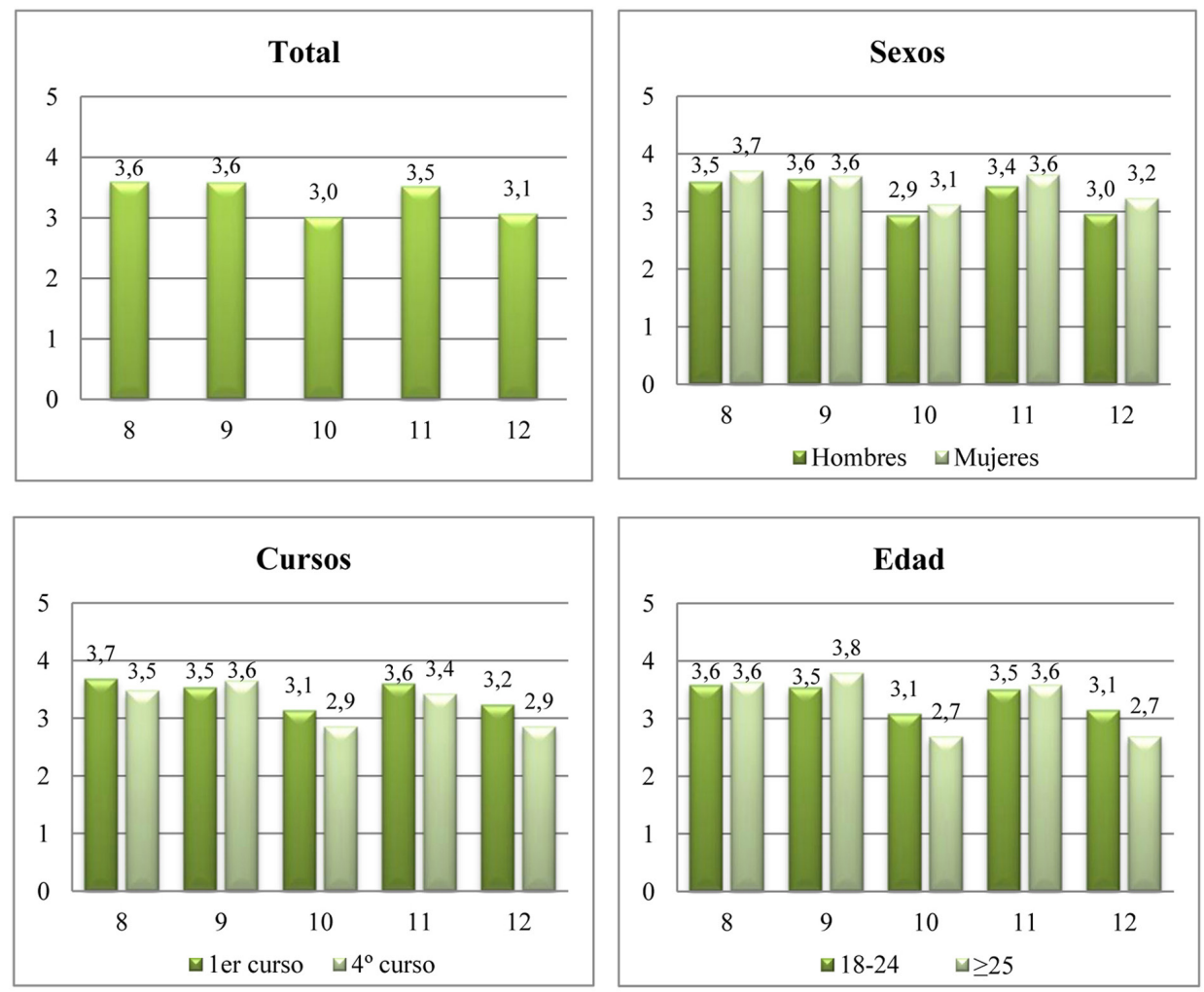

Figura 4: ítems con porcentajes de respuesta y promedio por categorías. Fuente: elaboración propia. 
En el cuestionario, introdujimos la idea de si los inicios de la agricultura habrían podido ser desarrollados por mujeres, considerando que, si durante el Paleolítico habrían sido las que mayoritariamente recolectaban, se les podría presuponer, por lo tanto, un mayor conocimiento sobre las plantas. Diferentes trabajos han abordado este razonamiento, cuestionándose, si la mayor parte de la arqueología tradicional asocia a las mujeres con la recolección, por qué no se les ha atribuido papel activo alguno en la transición al Neolítico (Watson y Kennedy, 1991; Gilchrist, 1999; DíazAndreu, 2005). Esta argumentación ha sido dada por válida por un reseñable $64 \%$ del estudiantado, con un $12 \%$ que se muestra en desacuerdo y un importante porcentaje, del $24 \%$, optando por la posición intermedia ni de acuerdo, ni en desacuerdo. Las alumnas tienden a mostrarse más de acuerdo que sus compañeros varones, con una pequeña diferencia de dos décimas, y el alumnado de cuarto algo menos de acuerdo que el de primero, también con esa pequeña diferencia.

Cuando se les plantea si en las sociedades prehistóricas los hombres también habrían desempeñado un papel importante en el cuidado y en el aprendizaje de su descendencia, el $63 \%$ del alumnado encuestado se muestra de acuerdo o muy de acuerdo. Con un $16 \%$ que se posiciona en contra, más del $21 \%$ opta por la posición intermedia. Las respuestas medias no varían en función del sexo, ni prácticamente en función del curso. Sólo se observa una cierta diferencia en función de la edad, posicionándose el alumnado de edad igual o superior a 25 años más de acuerdo que el más joven, con tres décimas. Es destacable esta mayoría de respuestas positivas obtenidas a pesar de que la imagen de los hombres durante la Prehistoria ocupándose de su descendencia no se encuentra en las representaciones tradicionales acerca de esta etapa histórica, como probablemente tampoco en el imaginario colectivo, al menos hasta la actualidad. Ejemplo de ello sería la sorpresa que suscitó la escena de un hombre con una criatura en brazos en la exposición del Museo de Prehistoria de Valencia "Las Mujeres en la Prehistoria" (Soler, 2009). En las representaciones visuales de escenarios prehistóricos, una de las formas más comunes en las que se representa a las mujeres es sosteniendo a un bebé en brazos y/o con otros niños y niñas alrededor. En cambio, salvo recientes excepciones como la ya referida, no se representa a los hombres asociados a criaturas (Gifford-Gonzalez, 1993), más allá de las escenas que muestran a hombres enseñando a niños varones tecnologías como la del fuego o la producción lítica (Moser, 1993; Allinger, 2007).

Respecto a la idea de que la mayor parte de la cerámica en época prehistórica sería fabricada por mujeres, nos encontramos con cifras muy similares a favor y en contra, pues si el $29 \%$ del alumnado la da por válida, un considerable $27 \%$ se muestra en desacuerdo o totalmente en desacuerdo, mientras que un notable $44,4 \%$ se decanta por la posición "ni de acuerdo, ni en desacuerdo". Con dos décimas de diferencia, los alumnos varones y el alumnado de cuarto curso se muestran ligeramente más en desacuerdo, siendo cuatro las décimas de margen con las que el grupo de igual o más de 25 años expresan también esta tendencia, la categoría empleada donde se observa una menor conformidad con que la producción cerámica hubiera estado mayoritariamente en manos de las mujeres. La fabricación de cerámica durante la Prehistoria reciente ha sido considerada como un trabajo realizado mayoritariamente por mujeres de acuerdo con la teorización de las llamadas actividades de mantenimiento (Picazo, 1997; Montón, 2000; Sánchez Romero, 2008; entre otros). Esta actividad suele ser representada como un trabajo femenino en las representaciones gráficas presentes, por ejemplo, en los museos, observándose que ello suele ocurrir cuando se trata de cerámica hecha a mano y salvo que se considere un trabajo "especializado" -como en representaciones de producción de cerámica argárica, donde en las ilustraciones se atribuye esta tecnología predominantemente a productores masculinos-. Del mismo modo, si se introduce el empleo del torno para la fabricación de cerámica en las representaciones arqueológicas, son hombres los que sistemáticamente se representan utilizándolo. Las excepciones, como la imagen escogida como portada del libro Museos arqueológicos y género (Prados y López, 2017), realizada por Arturo Asensio, son muy escasas. Así, observamos un rechazo mayor entre el alumnado cuando se les plantea la misma cuestión para época romana, cuando la posibilidad de que la producción cerámica fuese realizada por mujeres de manera mayoritaria es aceptada sólo por el 18,5\% (Mateo y Pastor, 2019), algo posiblemente relacionado con la asociación de este periodo con el uso intensivo 
del torno y la producción en serie.

Por el contrario, ante la frase "la producción del metal en la Prehistoria habría sido realizada mayoritariamente por hombres", se observa una mayor aceptación, con un 50\% del alumnado de acuerdo y un $9,3 \%$ muy de acuerdo. Sólo el $15 \%$ se posiciona en contra, mientras que un $26 \%$ opta por la posición intermedia. Se observa una mayor tendencia entre las alumnas a aceptar esta idea, con dos décimas más que los alumnos varones, la misma diferencia con que se muestra más de acuerdo el alumnado de primer curso que el de cuarto. Como ocurre con la fabricación de herramientas de piedra, la metalurgia, presente a partir de un determinado momento de la Prehistoria reciente, se encuentra representada como un trabajo absolutamente masculino. Ambas actividades son ejemplos paradigmáticos de tecnologías asociadas a los hombres de manera casi exclusiva y a las que se atribuye una decisiva importancia, reflejada en la propia denominación de las etapas de la Prehistoria, mantenida hasta hoy.

Por último, el alumnado del Grado en Historia valoró la idea, formulada también de forma categórica, de que en las sociedades prehistóricas hubieran sido los hombres los constructores de las viviendas. Al igual que ocurre con otras actividades laborales, son muy escasas las excepciones en las que no se excluye por completo a las mujeres en las representaciones de escenas de construcción en la Prehistoria reciente. Ante este planteamiento mostraron su conformidad el $38 \%$ de los y las estudiantes, manifestándose en contra un cercano 35,2\% y optando por la posición intermedia el $27 \%$. Los resultados de las alumnas muestran que ellas se posicionan de media algo más de acuerdo que sus compañeros varones en atribuir la construcción de viviendas a los hombres, con dos décimas de diferencia. El estudiantado de cuarto afirma estar menos de acuerdo que el de primero, con tres décimas de margen, al igual que el alumnado con edad a partir de 25 años respecto al más joven, con un promedio de 2,7 y de 3,1 respectivamente.

\section{Reflexiones finales}

Desde hace décadas se ha llamado la atención acerca de cómo las concepciones contemporáneas sobre las atribuciones de género a hombres y mujeres han sido frecuentemente trasladadas a las interpretaciones de la Prehistoria (Conkey y Spector, 1984; Conkey, 1991; DíazAndreu, 2005; entre otros). Este trabajo ha permitido conocer que entre el alumnado encuestado del Grado en Historia parecen estar presentes parte de estas concepciones que expresan una determinada distribución de las actividades laborales en la Prehistoria en función del sexo y en las que se observa la influencia de marcados roles de género. Así, el $60 \%$ del estudiantado se ha mostrado de acuerdo con que en tiempos prehistóricos serían los hombres quienes cazarían, mientras que las mujeres serían las que recolectarían. También el $60 \%$ ha dado por válido que la producción del metal sería realizada por los hombres. Más del $42 \%$ han afirmado estar de acuerdo con que en la Prehistoria, los hombres realizarían la mayor parte del trabajo, ya que las mujeres se dedicarían al cuidado de su descendencia. En estos tres casos, aunque con una pequeña diferencia, las alumnas se muestran incluso algo más de acuerdo que los alumnos.

En algunas de las cuestiones planteadas, como las tres que acabamos de resaltar, puede observarse una cierta diferencia en las respuestas en función del curso, pudiendo atribuirse, en general, una presencia algo menor de concepciones estereotipadas entre quienes van a terminar de cursar el Grado en Historia respecto a quienes lo comienzan ${ }^{7}$. No obstante, no es así en todos los casos ya que, por ejemplo, el alumnado de primer curso se muestra más de acuerdo que el de cuarto con la idea de que tanto mujeres como hombres habrían producido herramientas líticas.

Los dos ítems que han suscitado un mayor número de respuestas intermedias, "ni de acuerdo,

7 Como puede verse en las guías docentes y en los datos recogidos por Mónica Moreno Seco (2014), en algunas asignaturas del Grado en Historia de la Universidad de Alicante se han incorporado contenidos con perspectiva de género. Destaca una de las asignaturas optativas, «Historia y género», de cuarto curso. 
ni en desacuerdo", son los dos que afirman que serían las mujeres quienes desarrollarían una determinada tecnología o manifestación: la cerámica, con un $44 \%$ de respuestas sin posicionarse, que en el caso de las pinturas rupestres alcanza el 73\%. En este sentido, es relevante señalar como este alto porcentaje de indefinición a la hora de atribuir una actividad predominantemente al sexo femenino no se da de la misma manera en el caso de atribuirla a los hombres, como ocurre con la producción del metal y la construcción de viviendas, con un $26 \%$ y un $27 \%$ de posiciones intermedias respectivamente.

En los últimos años se están realizando estudios encaminados a analizar la percepción del estudiantado sobre la desigualdad entre hombres y mujeres, orientados mayoritariamente hacia su análisis en la actualidad, tanto en el ámbito universitario (Martín, Etura y Ballesteros, 2016; Aguaded, 2017; entre otros), como en otros niveles educativos, como la enseñanza secundaria (Aroca y Llano, 2006; González, 2009). Una exhaustiva investigación realizada en el alumnado de secundaria apuntó que, al mismo tiempo que las alumnas eran menos proclives a dar por válidos los enunciados machistas que los alumnos varones, un importante porcentaje de alumnas mostraban aceptación ante la relación entre las mujeres y lo "doméstico", al igual que optaban mayoritariamente por las profesiones típicamente femeninas (Aroca y Llano, 2006). Quizá esta tendencia pueda relacionarse con el hecho de que las alumnas encuestadas en nuestro estudio se muestren algo más de acuerdo que sus compañeros varones en que serían los hombres los que cazarían, realizarían la mayor parte de los trabajos, trabajarían el metal o construirían las viviendas.

En todo caso, la presencia de estereotipos de género actuales en las respuestas del alumnado del Grado de Historia no debe sorprender, si se considera la tradición androcéntrica que desde su nacimiento ha formado parte de los estudios históricos en general y de la Prehistoria en particular y que aún hoy perdura en buena medida. Además, los alumnos y alumnas tampoco son ajenos a los mensajes poderosos sobre los roles de mujeres y hombres en la Prehistoria presentes no sólo en la cultura popular, sino en ámbitos más especializados como los museos arqueológicos. Por todo ello, esperamos que estudios como el que presentamos contribuyan poco a poco a mejorar el conocimiento sobre la percepción del alumnado acerca de estos temas y a registrar sus actitudes y posicionamientos, un conocimiento que creemos necesario de cara a mejorar la investigación y la enseñanza de la Historia.

La imagen de debilidad y pasividad de las mujeres de la Prehistoria que aún hoy persiste está originada en un pensamiento patriarcal y continúa siendo alimentada por la reproducción de imágenes y modelos de escenas ambientadas en contextos prehistóricos con un importante carácter sexista. Es necesario continuar cuestionando los roles tradicionalmente considerados como masculinos y femeninos y trasladados a la Prehistoria sin pruebas que los avalen, y que, siendo este el caso, el abanico de actividades económicas sea planteado y analizado para ambos sexos (Moser, 1993). Además de no contemplar el trabajo de las mujeres, estas concepciones no sólo atribuyen unos roles de género determinados de carácter considerablemente presentista, sino que también cuestionan las capacidades de las mujeres (Spector, 1999; Owen, 2005). En muchos casos, las interpretaciones reflejan ideas contemporáneas que transmiten que el espacio de las mujeres es el doméstico y, por lo tanto, no el otro, el mundo "real", "exterior", el de la actividad y el trabajo, que ha sido establecido como dominio natural masculino. El hecho de que las mujeres sigan estando ausentes en las atribuciones a un sexo $u$ otro de diversas actividades económicas, como la caza y la pesca, la ganadería, la edificación y el desarrollo de distintas tecnologías, acaba implicando y transmitiendo que se las asume incapaces de desempeñarlas.

En definitiva, el trabajo presentado incide en la necesidad de incorporar la perspectiva feminista para tratar de acercarnos más a la realidad en estudio (Conkey, 2003; Sánchez Liranzo, 2008; Lozano, 2010), al permitir identificar y poner de manifiesto las asunciones que, generadas en una tradición patriarcal y sexista largamente arraigada, alteran la visión que tenemos de las sociedades del pasado. 


\section{Bibliografía}

Adovasio, J. M., Soffer, O. y Page, J. (2007). The Invisible Sex. Uncovering the true roles of women in Prehistory. New York: Smithsonian Books.

Aguaded, E. Ma (2017). Análisis de la presencia de sexismo en alumnado universitario. ENSAYOS, Revista de la Facultad de Educación de Albacete, 32 (1), 127-143.

Allinger, K. (2007). Fakt oder Fiktion? Genderspezifische Konnotationen archaäologischer Lebensbilder. En Fries, J. E., Rambuscheck, U. y Schulte-Dornberg, G. (eds.), Science oder Fiktion? Geschlechterrollen in archäologischen Lebensbilder. Bericht der 2. Sitzung der AG Geschlechterforschung während des 5. Deutschen Archäologen-Kongresses in Frankfurt (Oder), 2005 (pp. 45-62). Frauen-Forschung- Archäologie 7. Münster.

Aroca, F. J. y Llano, J. C. (2006). Actitudes de género en alumnas/os de ESO. Albacete: Observatorio Municipal de Igualdad de Oportunidades.

Bachofen, J. J. (1861). Das Mutterrecht: eine Untersuchung über die Gynaikokratie der alten Welt nach ihrer religiösen und rechtlichen Natur. Stuttgart: Verlag von Krais und Hoffmann.

Bolger, D. (2006). Gender and human evolution. En Nelson, S. M. (ed.), Handbook of Gender in Archaeology (pp. 453-502). Lanham: Altamira Press.

Bosch, E. y Ferrer, V. A. (2003). Fragilidad y debilidad como elementos fundamentales del estereotipo tradicional femenino. Feminismo/s, 2, 139-152.

Cintas-Peña, M., García Sanjuán, L. y Morell, B. (2018). Gender and Prehistory. Sexual division of labour in Spanish audiovisual productions. ArkeoGazte, 8, 75-99.

Conkey, M. W. (1991). Original narratives. The political economy of gender in Archaeology. En Di Leonardo, M. (ed.), Gender at the crossroads of knowledge: Feminist anthropology in the postmodern era (pp. 102-139). Berkeley: University of California Press.

Conkey, M. W. (1997). Mobilizing ideologies. Paleolithic "art", gender trouble and thinking about alternatives. En Hager, L. D. (ed.), Women in Human evolution (pp. 172-207). London: Routledge.

Conkey, M. W. (2003). Has feminism changed archaeology? Signs, 28 (3), 867-880.

Conkey, M. W. y Spector, J. D. (1984). Archaeology and the study of gender. En Schiffer, M., Advances in Archaeological method and theory, 7 (pp. 1-38). New York: Academic Press.

Dahlberg, F. (1981). Woman the gatherer. New Haven: Yale University Press.

Díaz-Andreu, M. (2005). Género y arqueología: una nueva síntesis. En Sánchez Romero, M. (ed.), Arqueología y género (pp. 13-51). Granada: Universidad de Granada.

Estioko-Griffin, A. y Griffin, P. B. (1981). Woman the hunter: the agta. En Dalhberg, F. (ed.), Woman the gatherer (pp. 121-151). New Haven: Yale University Press.

Farrell, A. D., Rabinowitz, J. A., Wallander, J. L. y Curran, J. P. (1985). An evaluation of two formats for the intermediate-level assessment of social skills. Behavioral Assessment, 7 (2), 155-171.

George, D. y Mallery, P. (2003). Spss for Windows step by step: A Simple Guide and Reference. 11.0 Update (4. ${ }^{a}$ ed.). Boston: Allyn \& Bacon.

Gero, J. M. (1991). Genderlithics: women's role in stone tool production. En Gero J. y Conkey, M. W. (eds.), Engendering Archaeology. Women in Prehistory (pp. 163-193). Oxford: Blackwell.

Gifford-Gonzalez, D. (1993). You can hide, but you can't run: Representation of women's work in illustrations of Palaeolithic life. Visual Anthropology Review, 9 (1), 22-41.

Gilchrist, R. (1999). Gender and archaeology: contesting the past. London: Routledge.

González, P. (2009). La otra prehistoria: creación de imágenes en la literatura científica y divulgativa. Arenal, 15 (1), 91-109.

Hernando, A. (2005). Mujeres y Prehistoria. En torno a la cuestión del origen del patriarcado. En Sánchez Romero, M. (ed.), Arqueología y género (pp. 73-108). Granada: Universidad de Granada.

Jardón, P. y Pérez, C. I. (2012). Representació del passat: ciencia i ficció. En Jardón, P., Pérez, C. y Soler, B. (eds.), Prehistòria i cinema (pp. 17-38). Valencia: Museu de Prehistòria de València. 
Jardón, P., Pérez, C. y Soler, B. (eds.) (2012). Prehistòria i cinema. Valencia: Museu de Prehistòria de València.

Kästner, S. (2009). Jagende Sammlerinnen und sammelnde Jägerinnen. Wie australische AboriginesFrauen Tiere erbeuten. Berlin: Lit Verlag.

Leibowitz, L. (1975). Perspectives on the Evolution of Sex Differences. En Reiter, R. R. (ed.), Toward an anthropology of women (pp. 20-35). Nueva York: Monthly Review Press.

Lerner, G. (1990). La creación del patriarcado. Barcelona: Crítica.

Lombo, A., Catalán, T., Palacios, S. y Parrilla, J. (2014). El Paleolítico en los dibujos animados: el universo de ficción prehistórica. El Futuro del Pasado, 5, 31-50.

Lozano, S. (2010). El hombre es la medida de todas las cosas. El tópico androcéntrico en Arqueología y las alternativas metodológicas feministas. Estrat crític, 5 (3), 18-29.

Martín, V., Etura, D. y Ballesteros, C. A. (2016). Igualdad de género en la Universidad: estudio del caso de los alumnos de Periodismo de la Universidad de Valladolid. Opción, 32 (11), 886-901.

Mateo, D. y Pastor, M. (2019). La desigualdad entre hombres y mujeres en la antigua Roma: un estudio sobre sus concepciones y conocimiento en el alumnado de Historia. Cuadernos de Arqueología. Universidad de Navarra.

Montón, S. (2000). Las mujeres y su espacio: una historia de los espacios sin espacio en la Historia. Arqueología espacial, 22, 45-59.

Moreno, M. (2014). Historia de las Mujeres y de Género en los estudios de Grado. Recuperado de http://aeihm.org/historia/historia-mujeres-genero-estudios-grado

Moser, S. (1993). Gender stereotyping in pictorial reconstructions of human origins. En Du Cros, H. y Smith, L. (eds.), Women in archaeology: a feminist critique (pp. 75-92). Canberra: Department of Prehistory, Research School of Pacific Studies, Australian National University.

Namakforoosh, M. N. (2000). Metodología de la investigación. México: Limusa.

Owen, L. (2005). Distorting the Past. Gender and the Division of Labor in the European Upper Paleolithic. Tübingen: Kerns Verlag.

Pastor, M. y Mateo, D. (2018). La desigualdad entre mujeres y hombres, en el pasado y en el presente. Un estudio preliminar sobre su percepción y conocimiento en el alumnado de Historia. El Futuro del Pasado, 9, 365-391.

Picazo, M. (1997). Hearth and home: the timing of maintenance activities. En Moore, J. y Scott, E. (eds.), Invisible people and processes. Writing gender and childhood into European Archaeology (pp. 59-67). London: Leicester University Press.

Prados Torreira, L. y Ruiz López, C. (eds.) (2017). Museos arqueológicos y género. Educando en igualdad. Madrid: Servicio de Publicaciones de la Universidad Autónoma de Madrid.

Querol, Ma A. y Hornos, F. (2015). La representación de las mujeres en el nuevo Museo Arqueológico Nacional: comenzando por la Prehistoria. Complutum, 26 (2), 231-238.

Rodríguez, R. y Serrano, L. (2005). El concepto de matriarcado: una revisión crítica. Arqueoweb, 7 (2).

Roque, $M^{a}$ A. (2017). Las amazonas, la contribución de un mito griego al imaginario patriarcal. Quaderns de la Mediterrània, 24, 187-193.

Ruiz, G. (1997). Héroes de piedra en papel: la Prehistoria a través del cómic. Complutum, 8, 285310.

Ruiz, G. (2010). Los valores educativos de la prehistoria en la enseñanza obligatoria. $M A R Q$, Arqueología y Museos, 4, 161-179.

Ruiz, G. y Álvarez, J. R. (1997). La Prehistoria enseñada y los manuales escolares españoles. Cumplutum, 8, 265-284.

Sánchez Liranzo, O. (2008). El debate teórico en los estudios de la arqueología del género y su incidencia en la Prehistoria. En Prados, L. y Ruiz, C. (eds.), Arqueología del género. 1er encuentro internacional en la UAM (pp. 43-60). Madrid: Universidad Autónoma de Madrid.

Sánchez Romero, M. (2008). Actividades de mantenimiento, espacios domésticos y relaciones de género en las sociedades de la Prehistoria Reciente. En Prados, L. y Ruiz, C. (eds.), 
Arqueología del género. 1er encuentro internacional en la UAM (pp. 93-103). Madrid: Universidad Autónoma de Madrid.

Sassaman, K. E. (1998). Lithic technology and the hunter-gatherer sexual division of labor. En Hays-Gilpin, K. y Whitley, D. S. (eds.), Reader in Gender Archaeology (pp. 159-171). London: Routledge.

Slocum, S. (1975). Woman the gatherer: male bias in anthropology. En Reiter, R. (ed.), Towards an anthropology of women (pp. 36-50). New York: Monthly Review Press.

Soler, B. (2009). De la investigación a la difusión: el museo como vehículo de mediación. Arenal, 15 (1), 179-194.

Soler, B. (2012). ¿Eren així les dones de la prehistòria? En Jardón, P., Pérez, C. y Soler, B. (eds.), Prehistòria i cinema (pp. 83-99). Valencia: Museu de Prehistòria de València.

Spector, J. D. (1999). ¿Qué significa este punzón? Hacia una arqueología feminista. En Colomer, L., González, P., Montón, S. y Picazo, M. (eds.), Arqueología y teoría feminista. Estudios sobre mujeres y cultural material en arqueología (pp. 233-256). Barcelona: Icaria.

Venegas, A. (2017). La Prehistoria a través del videojuego: representaciones, tipologías y causas. Espacio, tiempo y forma. Serie I Prehistoria y Arqueología, 10, 13-36.

Watson, P. J. y Kennedy, M. C. (1991). The development of horticulture in the Eastern Woodlands of North America: women's role. En Gero, J. M. y Conkey, M. W. (eds.), Engendering archaeology (pp. 255-275). Oxford: Blackwell.

Wood, B. (1996). Wot! No dinosaurs? Interpretation of Prehistory and a new gallery at the Museum of London. En Devonshire, A. y Wood, B. (eds.), Women in Industry and Technology, from Prehistory to the present day. Current research and the museum experience (pp. 53-62). London: Museum of London.

Zihlman, A. L. (1981). Women as shapers of the human adaptation. En Dahlberg, F., Woman the gatherer (pp. 75-119). New Haven: Yale University Press. 



\section{Panta Rei}

PANTA REI es una revista digital de investigación orientada a la Historia y otras ciencias afines. Su principal objetivo es la transmisión del conocimiento científico, dando una oportunidad también a los jóvenes investigadores que quieren abrirse camino en el estudio de las ciencias humanas y sociales. Se compone de estudios originales relacionados con la disciplina histórica así como su didáctica y difusión. Las diferentes secciones que componen la revista son: artículos de investigación, entrevistas a profesionales, recensiones de monografías de actualidad y crónicas de congresos o eventos científicos relevantes.

Todos los artículos publicados son objeto de un proceso de revisión a cargo de un mínimo de dos evaluadores, que se consideran expertos en el ámbito temático del artículo propuesto. Nuestro deseo es poder ofrecer unos contenidos rigurosos, de calidad y de interés.

EI CEPOAT (Centro de Estudios del Próximo Oriente y la Antigüedad Tardía de la Universidad de Murcia) es la institución encargada de la coordinación y gestión de la revista, desde donde anualmente se lanzará la convocatoria para aquellos que estén interesados en publicar sus trabajos, siempre relacionados con la Historia, Arqueología, Historia del Arte, Didáctica de la Historia, etc.

PANTA REI is a digital journal focused on History and other sciences related to it. Its main objective is the transmission of scientific knowledge by giving also an opportunity to young researchers who want to make their way in the study of human and social sciences. It is composed by original studies related to History, as well as its didactics and promotion. The different sections of this journal are: research articles, interviews to professionals, recensions on monographs about current issues and reports about congresses or relevant scientific events.

All the articles published are subject to a revision process carried out by a minimum of two reviewers who are considered to be experts in the field of the article proposed. Our wish is to offer rigorous contents with quality and being of interest to the reader.

CEPOAT (Centre of Studies of the Middle East and Late Antiquity of the University of Murcia) is the institution in charge of the coordination and management of this journal. This is the centre from where the call for papers will be launched for all the people interested in publishing their papers, always related to History, Archeology, Art History, Teaching History, etc. 


\section{Normas de Publicación}

El autor se compromete a enviar trabajos originales, que no se encuentren publicados en otras revistas ni en otros idiomas. Así mismo, el mismo artículo no podrá ser presentado en otras revistas mientras dure el proceso de evaluación.

\section{Envío y presentación de originales}

Los artículos se enviarán exclusivamente a través del correo electrónico a la dirección pantarei@um.es. Los textos serán enviados en formato DOC y las imágenes en formato JPEG o TIFF, y con un tamaño mínimo de 2000 px. Éstas no aparecerán incorporadas en el texto, sino enviadas en archivo aparte y correctamente numeradas según su posición en el texto. Junto al trabajo, se rellenará y enviará un documento aparte en el que se especifiquen los datos del autor siguiendo el modelo disponible en la página Web de la revista.

Para la redacción de los trabajos se tendrá en cuenta el Manual de la American Psychological Association, en su sexta edición. La extensión máxima de los trabajos será de 30 páginas. La tipografía será Arial 11, con interlineado sencillo y sin espacio alguno entre párrafos. El texto deberá ir justificado a ambos márgenes y sin sangría en los primeros párrafos. Los márgenes serán de $2,50 \mathrm{~cm}$. En los casos en los que fuera necesario incorporar notas, éstas irán a pie de página, enumeradas consecutivamente, con tipografía Arial 10, interlineado sencillo y justificadas a ambos márgenes.

Una información más detallada se encuentra disponible en la página http://www.um.es/cepoat/ pantarei.

\section{Proceso de valoración y evaluación}

Una vez recibidos los trabajos, la Revista realizará una primera valoración. Si el trabajo enviado se ajusta a las normas de presentación propuestas, la temática es coincidente con la línea editorial de la revista y posee la calidad científica necesaria, será remitido al consejo asesor para una primera evaluación. Si no es así en este primer paso se puede rechazar directamente los documentos que incumplan claramente la línea editorial.

Será el Consejo Asesor quien indique a la revista la originalidad, relevancia, estructura, redacción, aparato bibliográfico, etc. del trabajo enviado y, para ello, se designará a dos revisores expertos externos que evaluarán cada uno de los trabajos, que pueden formar parte (o no) de este Consejo Asesor. La selección de los revisores se ajustará a la temática y características metodológicas del trabajo. El nombre y filiación de los autores serán eliminados del trabajo para su revisión, así como los revisores actuarán de manera anónima y confidencial.

Los revisores deberán rellenar un informe de evaluación que centrará su atención en aspectos tales como características formales, originalidad y novedad de los trabajos, relevancia de las propuestas y los resultados, calidad metodológica y validez científica.

Una vez terminado el proceso se decidirá la aceptación o no de los mismos y su publicación en el número que sea pertinente, así como las modificaciones susceptibles de ser realizadas para su final publicación. Dicha notificación se enviará únicamente por correo electrónico, en un plazo máximo de seis meses. 


\section{Publishing rules}

The author is committed to submit original papers not having been published in other reviews or in other languages. In this way, it is not allowed for the same paper to be presented in other reviews during the evaluation process.

\section{Submission and presentation of originals}

The articles will be exclusively submitted by email to pantarei@um.es. The texts will be submitted in DOC format and the images in JPEG or TIFF format, and with a minimum size of 2000 px. Images will not be integrated in the text but sent in another file and properly numbered according to their position in the text. Attached to the paper, a document will be filled out and sent where the author's data will be specified following the model available on the website.

The sixth edition of the Manual of the American Psychological Association will be taken into account for the writing of the papers. The length of the papers must not exceed 30 pages. Typography will be Arial 11 , with simple line spacing and no space between paragraphs. The text must be justified on both margins without indentation in the first paragraphs. Margins size will be $2.50 \mathrm{~cm}$. Where it could be necessary the incorporation of notes, they will be at the bottom of the page, consecutively numbered with typography Arial 10, simple line spacing and justified on both margins.

More detailed information is available on the website: http://www.um.es/cepoat/pantarei.

\section{Examination and assessment process}

The Journal will submit the papers to a first examination once received. If the paper follows the presentation guidelines, the subject agrees with the editorial line of this journal, and possess the scientific quality required, it will be sent to the advisory council for a first assessment. If not, the documents which clearly fail to complete the editorial line may be rejected straightaway in this first step.

The Advisory Council will indicate the originality, relevance, structure, writing, bibliography, etc. of the text to the journal; for this purpose, two outside experts will be designated to review the papers; these experts can be (or not) part of this Advisory Council. The selection of the experts will adjust to the subject and methodological characteristics of the paper. Name and affiliation of the author will be eliminated from the text for its review, in this way experts will act anonymously and confidentially.

The experts will fill out an assessment report which will focus on aspects such as formal characteristics, originality and novelty of the papers, relevance and results of the proposal, methodological quality and scientific validity.

Once the process is finished, the acceptance or not of the papers and its publication in the corresponding edition will be decided, as well as the modifications that may be done for its final publication. This notification will be sent by email within 6 months maximum. 


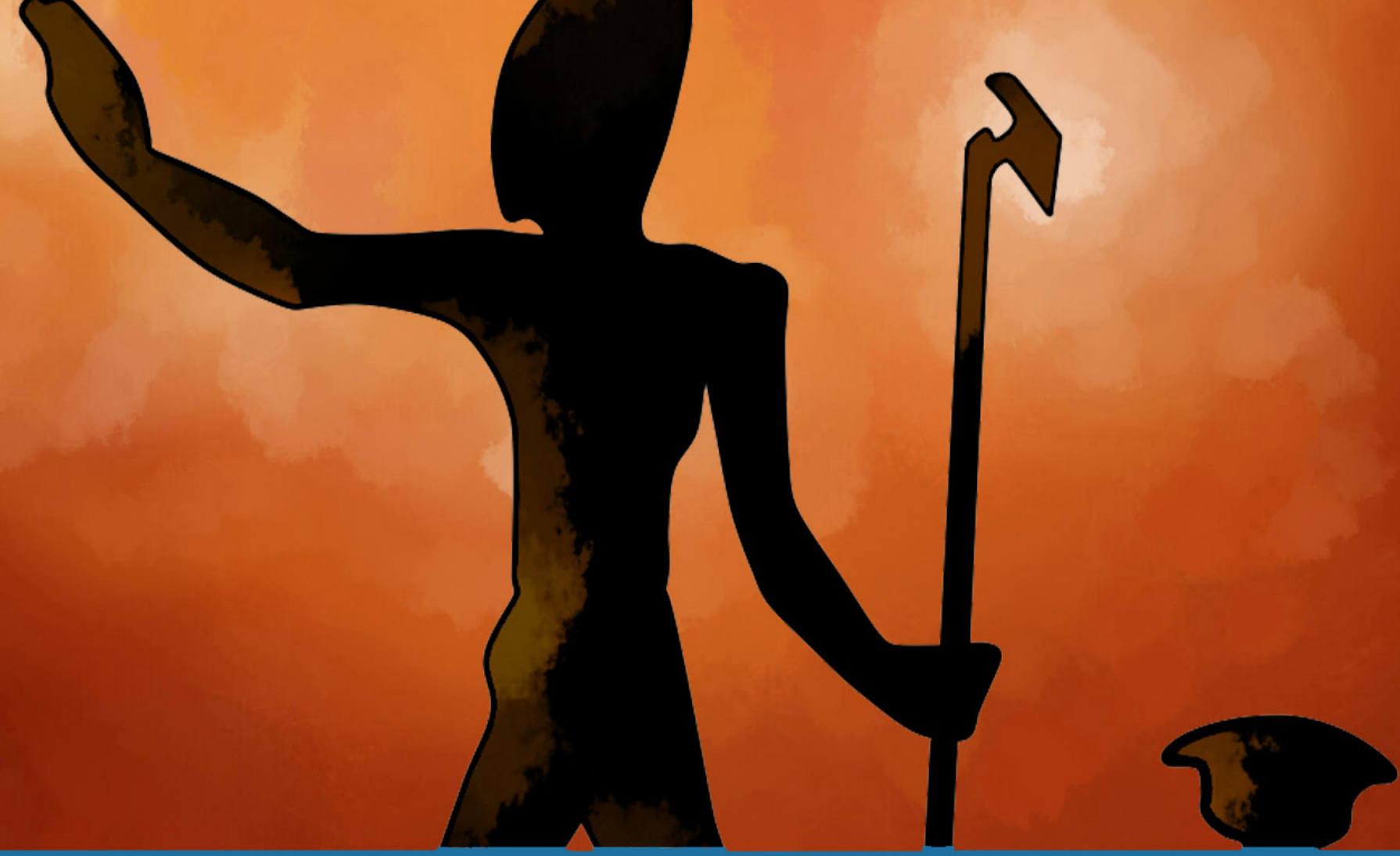

GepOA

centro de estudios de

próximo oriente y la

antigüedad tardía 